Interviews 


\section{An Interview with Anthony Pym}

\section{Aditya Kumar Panda}

Anthony Pym (abridged as AP) is a scholar in the field of Translation Studies. He is currently the distinguished Professor of Translation and Intercultural Studies at the Rovira i Virgili University in Tarragona, Spain, and Professor of Translation Studies at the University of Melbourne, Australia. Aditya Kumar Panda (abridged as AKP) interviews Pym on various theoretical underpinnings concerning translation and reciprocal nature of theory and practice in translation. His interview starts with a fundamental question of what a translation is.

AKP: You have mentioned anuvaad being a word Indians use for translation which has the meaning of repeating or saying later. The Western notion of translation has not been encapsulated in this anuvaad. Indians did attribute transcreation, adaptation to translation. Will you consider transcreation or adaptation as translation? If so, how would you define translation?

AP: There are many different translation concepts throughout history and across cultures, and most of them seem not to make a systematic distinction between translating and retelling or adaptation. Harish Trivedi tells me that prior to British influence there was actually no concept like Western translation in the cultures of the subcontinent, which for me suggests that there was a Western translation form that was disseminated along with modernity. As a rule of thumb, when the railway lines appeared, so did traces of this Western translation form. 
For me, it is not hard to define the Western translation form. First, it uses the alien-I: when the translating translator says "I am tired", it is not the translator who is tired. This is interesting, since it means that translating translators, like acting actors, do not have a first-person voice; they work with a repressive discursive structure that can be struggled against. Second, the Western form incorporates a maxim of quantitative dependence: for each increase in textual length, it is assumed there is an increased length in an anterior text. This doesn't mean that the texts have the same length, of course, but there is a relation of dependence. And third, it is assumed that there has been a switch of languages. Those three features can define the Western translation form (Gideon Toury formulates the features in a different way, but they do the same job). The alien-I is a discontinuous variable; the other two are continuous and allow for a prototype approach. All three function as maxims in the Gricean sense: their transgressions can produce meaning effects.

Is that how I personally define translation? When I translate or interpret for my clients, yes, mostly it is, since I like to be paid and those are the unspoken maxims that regulate our transactions. As for research, well, I tell my doctoral students that they can use any terms they like as long as they make the meanings clear. So if I am talking about the contemporary Western kind of translation, the above description fits with the way I am using the term. But I am happy to talk about any other form as well.

That said, I do not believe the Western form is a particularly 
good communication solution these days. Thanks to technologies, to social complexity and to ubiquitous mobility, cross-cultural communication problems are increasingly solved by the use of lingua francas, code-switching, intercomprehension (bilingual conversations) and badly understood free online translation technologies, for which we have to teach post-editing instead of translation. Professional mediators have become something of an anachronistic luxury, to be reserved for high-risk communication only. The study of translation is no longer sufficient in itself.

I think this also holds when we go back and work on periods prior to the Western translation form. If we only look at texts that meet our current sense of "translation", we are missing out on most of the actual transmission and rewriting activities, especially the spoken activities of which there are only traces in the written texts. In that historical frame, I think it makes sense to work on cross-cultural communication in general, and to adopt a disciplinary name like "intercultural studies". I suspect that such a terminological shift is intellectually more honest than pretending that translation is and always was everywhere.

There is a further rider here. People who currently use the term "translation" in increasingly wider and less precise senses risk theorizing themselves out of pertinence. When Edwin Gentzler, for example, proclaims the advent of "posttranslation studies", what you mostly find is good old Comparative Literature with a newish name. Similarly, "cultural translation" is often just a name for cultural studies that have become aware there is more than one culture and that things move. There is a long etcetera of pseudo- 
intellectual pap that insists on finding translation everywhere, in all texts, in all thought processes, in all possible modes of liberation.

I suspect that Translation Studies, as an academic discipline, owes most of its success to the enrolment of students who want to learn how to translate and interpret and get paid for it. The sad part of the wider uses of "translation" in pedagogical contexts is that we are now misusing the students' aspirations as institutional support for our own intellectual pretensions.

AKP: Scholars always discuss various theories of translation and issues in the practice of translation. In translation, theory and practice go hand in hand. They are mutually inclusive and complement each other. How would you respond to the reciprocity between the practice and the theory of translation?

AP: I do not like to teach translation theory as such at Undergraduate or Masters level. For undergraduate students, the ideal class is when students come up with different renditions, you get them to argue with each other, then they find they need words to describe the things they are arguing about. That's when you can offer a few terms and concepts, or some established arguments, in order to develop the kind of theorizing that evolves from practice.

At Masters level, I insist there is a third term that runs across this false division of theory from practice. I am referring to research. I try to get students to do basic empirical research on their own translation processes, or to experiment with different ways of translating and to compare the results, or to look around and see how translation is actually being used in 
business or in websites, for example. And then I show them what translation scholars have found when doing research on the same variables, mostly with the integration of a few models and concepts. That is a way of conducting the translation practice class in a non-authoritarian manner: I don't know what the best translation is, or the best way of translating, or the definitive social role of translation, so let's find out together and then look at what empirical research has found.

I only teach theory as such at doctoral level, when candidates really have to learn how to think clearly and how to navigate through the standard arguments.

AKP: Do universal translation theories exist? Could dynamic and formal equivalence be applied across cultures? These days translators try to apply theories of literary translation to nonliterary translation. Can there be a translation theory across the types of translation?

AP: I am not really interested in aspirations to universalism. I think it is far more important to identify problems and work on solutions to those problems. If the problems extend over time and across cultures, then some solutions might travel along the same tracks, and that is all well and good. But it is just as noble to seek local solutions to local problems.

I do not think any of the binary concepts, such as formal correspondence versus dynamic equivalence, attain more than a tautological universality. It is relatively easy to formulate a translation concept, model two alternatives, and fool yourself into thinking the result is universal. For Eugene Nida, the formal/dynamic model did the historical work of turning Bible 
translation towards the concerns of receiving communities, breaking with start-text fixation. But that dialectic work is not required in other cultural situations, particularly with respect to translations into major cultures. In those cases, it is usually more fruitful to cut the cake in other ways, and there are rarely translation problems for which there are just two viable solutions.

On the other hand, there is nothing wrong with picking up concepts or models developed for one problem and trying to apply them to others. When you are trying to solve a problem, you accept ideas and help from wherever they can be found. There is no reason why a binary pair formulated for Bible translation should not be applied to literary or technical texts, for example, just as there is no reason why ideas that talk about literature should not prove useful in other discursive fields. The transfers and applications will never be neat or straightforward, but the encounters between discursive fields are often stimulating.

The idea that each discursive field somehow has its own translation theory seems to me to be terribly petty, divisive, and conducive to a fractious interdisciplinarity at best. It was rife in the Russian theorizing of the 1950s, for example, with results that were scarcely edifying.

AKP: Translation Studies scholars don't agree that every translation has a purpose. Most of the theorists of Skopos theory don't find any Skopos behind a literary translation. Would you agree with them?

AP: I am not aware of the theorists you are referring to, but I seem to remember Vermeer constructing something similar as a 
straw-man argument. In any case, one could use Kantian Zwecklosigkeit, the idea that the aesthetic text has no aim beyond aesthetic pleasure, to argue that there is no Skopos for a literary translation. I would prefer to say that the aesthetic text particularly lends itself to many possible readings, and thus to many possible purposes, but I suspect that this amounts to much the same critique at the end of the day.

For me, the place where the Skopos argument falls down is the supposition that there is just one purpose for any action, be it literary or otherwise. I think this is an absurdly essentialist article of faith. Most of our actions are motivated by several purposes at once (think of the many minor reasons why we are producing this dialogue, for example); we are constantly hedging our bets, seeking trade-offs and exploring the unknown, in ways that are far more complex than any simple purpose could ever be.

AKP: Translation does not exist as a recognized object in the world. It is there in the form of a writing or in the form of a book. The layman knows it as a poetry, as a novel, as a story, as a document. How would you make it visible where someone would immediately recognize a translation?

AP: I'm not sure I understand the question. There are cultures where all texts are considered translational to a degree, so there is no separate category for translations; there are other cultures where translations are clearly marked as such, on covers, in the translator's name, and often in the foreignized stylistics. It does not seem excessively difficult to have translations marked as such, but first you need a social translation concept that separates clearly between translations 
and non-translations. That kind of concept may not be available, or may not be desirable.

AKP: Can you train a translator whose language you have never mastered?

AP: You can help someone train themselves. And if you have at least two students who share the same language pair, you can help them monitor their progress.

AKP: The National Translation Mission organizes training programme for the translators where multilingual heterogeneous group of speakers do participate. In this set up, it is impossible to have an instructor who knows about all the languages the participants speak of. What would you suggest for training and evaluating them?

AP: This is something I have been working on for the past eight years or so, specifically in a multilingual practicum class in Monterey, California. A report on this ("Teaching translation in a multilingual practicum") is available on my website but I can summarize the main points here.

First, when instructors do not know the students' language pair, they should focus on translation processes, not products. You should make the student aware of how they are translating, how they can organize their work differently, and thus how they can try to improve. This concerns aspects such as using translation memories, post-editing machine translation output, documentation, web searches, integrated revision processes, reversing directionality, and team translating. Many of these aspects are best taught through students making screen recordings of their performances, 
then playing them back at four times the original speed so that they can see where they go wrong and especially how they lose a lot of time.

Second, the quality of translation products can be controlled to a certain extent through peer revision, if and when you have at least two students with the same language pair. Rather than have a definitive model translation to which students should aspire - there are always several good solutions to any translation problem - it is best to have students revise each other's translations right after each has translated either the same text or a parallel text rendered in the opposite language direction. That is, each student checks on the other, in the form of a revision exercise that should lead into dialogue.

This second aspect is very valuable in itself. Thanks to the growing use of translation technologies, revision is now one of the major things we have to teach, as is the post-editing of machine translation output. Those are skills that can be developed quite well in the multilingual practicum class, if and when all students can at least work into a shared language.

AKP: I got the idea of translation as a "move" from your book, Translation and Text Transfer. What is it that moves in translation? This moving also causes many transactions to take place and it may bring out new ideas where we may be able to look at ourselves critically. Translation causes movements. It is not only a static text or idea but also a dynamic progression of human endeavour. How would you respond to this? 
AP: Translation happens because something (or someone) has moved or is meant to be moved. Translation is thus caused by material movements, prior to its own work on semiotic movement. That simple proposition was, for me in 1980 or thereabouts, a way to think about translation in very materialist terms, without assuming systems or their boundaries; it was the central idea in a dissertation on the political economy of translation. I still think this is a useful way to think about translation: if you use material movement as a basis for your categories, you do not have to assume axiomatic boundaries between the languages and the cultures in play; you track the movements and let those movements reveal the boundaries as moments of resistance and transformation.

I hesitate, however, to claim that movement in itself entails some kind of ethical benefit. The traveller can suffer from the blindness of assumed superiority, or can just as blindly attribute assumed prestige to the other. There is no necessary self-criticism involved; nothing indicates that the more translations we have, the closer we come to earthly paradise.

The best one could argue, I believe, is that transfers between cultures are a necessary part of avoiding the stagnation or death of cultures. This has been argued by Jared Diamond and Itamar Even-Zohar, and there are indeed cases where cultures have died because of isolation from other cultures. On this view, translation would be useful for helping maintain cultural diversity. To make any braver claims, we would have to know what is being translated, and how.

AKP: Language is infinite with a finite numbers of rules as our linguist has postulated. Our language conventions are made 
by us. No native speaker of a language can speak of the cent percent of that language. An equivalent can be challenged anytime. It is not only the ideal equivalent that interrogates itself but also any equivalent can be challenged. How would you perceive the unstable position of equivalents in a language or in a translation?

AP: Potential equivalents are produced by translations; they do not exist prior to the moment of translation. The belief in equivalence, as a valid and durable relationship, is thus a fiction produced in the reception of translations, basically as a matter of convenient expedience. I don't think equivalence has anything to do with knowing the whole of a language. Nor does translation for that matter. There is a fundamental indeterminacy in language use, I believe, and equivalence beliefs are a practical way of communicating in spite of that.

It is no different in the economy. No one commands the entirety of transactions in an economic system, and there is systemic fluctuation in exchange values of all goods and services, but we still accept the value of a banknote in our daily transactions.

AKP: We have been using the translation procedures formulated by Vinay and Darbelnet for decades in teaching the techniques of translation in the classroom. Are these techniques sufficient? Can we apply these techniques across languages?

AP: This is a question addressed in my book Translation Solutions for Many Languages, where I generally ask whether typologies like Vinay and Darbelnet's are different for each language pair. So I compared the various typologies developed for Russian, Chinese, German, Slovak, Czech, and 
so on, as well as the Spanish and English typologies directly inspired by Vinay and Darbelnet's work on French.

My general finding is that the differences between the typologies have more to do with varying translation concepts and linguistic politics than with differences between the languages themselves. There are some obvious differences, of course: for work with Chinese or Japanese, for example, more attention has to be given to re-segmentation (the breaking or joining of sentences) and to various ways of producing loans (especially phonetic imitation or semantic recomposition). Also, work between European and Asian languages tends to centre around what Vinay and Darbelnet termed "transposition" and "modulation", whereas the French linguists assumed that what they called "literal translation" was the starting point.

In the end, though, the categorization of the actual solutions is not determined in any close way by the language structures themselves. It has more to do with what is pedagogically efficacious for certain learners at certain levels, and how a particular translation culture places values on foreign languages.

AKP: In your recent book Translation Solutions for Many Languages, why did you give the subtitle "Histories of a flawed dream"?

AP: The main flaw, I think, is the pretension to produce a typology that works for all languages, for all translation cultures, and for all time. There are several reasons why this aspiration to the universal fails. Not only are our languages indeterminate in their relation with meaning and value, but concepts of 
translation themselves change with cultures and epochs.

You might be able to propose a particular solution that will work for all languages and in all directions. Established technical terms, for instance, tend to be standardized across all languages that share the technology, and are made so by authoritative power structures (as in the Microsoft Glossaries). However, someone can always come along and say that what you are describing is not "real" translation or "translation proper", in this case perhaps because there is no real choice for a translator to make: terminology is not the same thing as translation, I suggest. So the Universalist would have to look for an authoritative power structure that can impose on everyone the one true meaning of the word "translation", but personally I cannot envisage any such instance of authority. That particular dream is thus flawed, and fatally so.

AKP: Translation was shunned from language-learning classes. But is it being re-introduced in many countries? Did the translation policy fail in early years or was it the methodology that was failed to keep translation as a language learning skill?

AP: I'm not sure that translation activities are actually being reintroduced in any massive way, although there are certainly increasing calls for reconsiderations of the way translation has been excluded by ideologies of linguistic immersion or communicative language teaching.

There are several reasons for this trend. I think translation and interpreting (or "linguistic mediation" as a wider set of skills) are things that students want to learn at the more advanced 
levels, so there is no reason not to teach them. There are also common-sense arguments based on the fact that adult beginners tend to use "mental translation" when they start learning a foreign language anyway. Many of the arguments in favour of immersion somehow assumed that all learners were young children.

I think the important point to bear in mind here is that there are many kinds and levels of translation. The kind of simple equivalence used for some basic vocabulary acquisition has nothing to do with the use of translation as a fully communicative activity in the classroom, or with the kinds of translation activities that inductively introduce and elucidate the differences between grammatical systems, or again with the complex creativity involved in the translating of texts at the highest level, when the advanced leaner activates linguistic and communicative skills in two languages and on many levels at once. Most of the arguments against translation have been based on the misleading idea that it is just a word-replacement exercise. Our first task is to show that translation is much more than that, and that communicative translation can be used in a wide range of classroom activities.

However, I would not claim that students who use translation thereby learn better or faster, and I certainly would not argue that translation activities enhance fluency, for example. The best we can claim, on the basis of the few empirical studies that test the use of communicative translation as opposed to non-translational activities, is that translation does no harm, and that is an extra set of skills that students generally enjoy learning. 
Part of the problem here is historical. There is the widespread idea that language learning up to the later decades of the nineteenth century was exclusively based on translation, on the so-called "grammar translation" method, which was followed by the use of immersion and communicative techniques towards the end of the century. However, when I went back and actually looked at the nineteenth-century textbooks for learning European languages, I was surprised to find that almost all of them proposed a mixture of spoken and written activities, with a range of translation exercises constituting just one part of the mix.

Another relative surprise came when Kirsten Malmkjær and I did a study for the European Commission in 2012-13. We found that the countries in Europe with the highest scores for learning English are generally those with the most reported use of translation in the classroom, although the teachers in Germany prefer to speak of "mediation" rather than "translation". That is why I would claim that translation does no harm, but I would also insist that it has to be mixed with other teaching activities, and that its pedagogical use should start from its spoken forms. 